\title{
PRÁCTICAS DE LECTURA Y ESCRITURA: ESTRATEGIAS DE INTERVENCIÓN DIDÁCTICA
}

\author{
READING AND WRITING PRACTICES: \\ DIDACTIC INTERVENTION STRATEGIES
}

María Teresa Sanséau.

Educación, Comunicación, Lingüística. Instituto Superior de Formación Docente № 22 "Adolfo Alsina"

Olavarría, Buenos Aires, Argentina. mteresanseau@gmail.com

Belén Fernández Massara

Educación, Comunicación, Lingüística. Instituto Superior de Formación Docente № 22 "Adolfo Alsina"

Olavarría, Buenos Aires, Argentina. micaiara@yahoo.com.ar

María Cecilia Zampatti.

Educación, Comunicación, Lingüística. Instituto Superior de Formación Docente № 22 "Adolfo Alsina" Olavarría, Buenos Aires, Argentina. mczampa11@gmail.com

Sandra Alberdi.

Educación, Comunicación, Lingüística. Instituto Superior de Formación Docente № 22 "Adolfo Alsina" Olavarría, Buenos Aires, Argentina. alberdisandra@hotmail.com

Resumen: Este artículo presenta algunas conclusiones del proyecto Prácticas de lectura y
escritura en el 2 do. Ciclo de Educación Primaria, en el marco de los Proyectos de Investigación
Pedagógica “Conocer para incidir sobre las prácticas pedagógicas" (Instituto Nacional de
Formación Docente, Ministerio de Educación). El objetivo general es analizar las prácticas y las
representaciones vinculadas a la comprensión lectora y producción textual en el 2 do. Ciclo de la
Educación Primaria y en el Espacio de la Práctica de la Formación Docente, en el área Prácticas
del Lenguaje. Seleccionamos las Escuelas Primarias $\mathrm{N}^{\circ} 8$ y N 59 del distrito de Olavarría (Buenos
Aires, Argentina) en el período $2016-2017$. El trabajo resulta de un diseño metodológico
fundamentalmente cualitativo, de tipo exploratorio, teniendo por objeto la generación de teoría
(Teoría Fundamentada). 
Verificamos, en primer lugar, los desfasajes recurrentes entre las representaciones y lo que concretamente se realiza en el aula. En segundo lugar, docentes en ejercicio y docentes residentes ponen de manifiesto diferentes propuestas y estrategias de enseñanza sobre la lectura y la escritura. Por último, concluimos que la literatura presenta un claro predominio como ámbito de intervención didáctica, afectando la formación en el lenguaje en su funcionamiento social y sus usos.

Palabras clave: lectura, escritura, intervención didáctica, innovación pedagógica, representaciones docentes.

Abstract: This article presents some conclusions of the project Practices of reading and writing in the 2nd. Primary Education Cycle, within the framework of Pedagogical Research Projects "Know to influence pedagogical practices" (National Institute of Teacher Training, Ministry of Education). The general objective is to analyze the practices and representations related to reading comprehension and textual production in the 2 nd. Cycle of the Primary Education and in the Space of the Practice of the Teacher Training in the area Practices of the Language. We selected the Primary Schools $\mathrm{N}^{\circ} 8$ and $\mathrm{N}^{\circ} 59$ of the district of Olavarría (Buenos Aires, Argentina), in the period 2016-2017. The work results from a fundamentally qualitative methodological design, of an exploratory type, having as its object the generation of theory (Grounded Theory).

We verify, first, the recurrent mismatches between the representations and what is concretely done in the classroom. Second, teachers in practice and resident teachers show different proposals and teaching strategies on reading and writing. Finally, we conclude that literature has a clear predominance as a didactic intervention field, affecting language training in its social functioning and its uses.

Keywords: reading, writing, didactic intervention, pedagogical innovation, teaching representations.

\section{INTRODUCCIÓN}

Este estudio responde al proyecto Prácticas de lectura y escritura en el 2do. Ciclo de Educación Primaria, resultante de la convocatoria de los Proyectos de Investigación Pedagógica "Conocer para incidir sobre las prácticas pedagógicas" (Instituto Nacional de Formación Docente, Ministerio de Educación). Iniciamos el proceso investigativo a partir de ciertas tensiones surgidas entre practicantes y docentes orientadores/as en torno al abordaje de la lectura y la escritura en el 2do. Ciclo de la Educación Primaria. Nos interesó indagar estas prácticas y las representaciones asociadas a ellas, para generar conocimiento teórico, pero también para incidir en la formación docente de los/las estudiantes, atendiendo a la propuesta curricular del área Prácticas del Lenguaje.

Apuntamos a la producción de conocimiento teórico del campo de la Formación Docente y sus posibilidades de transferencia a las prácticas formativas como a la enseñanza en el nivel primario. La producción de conocimientos además de dar respuestas e insumos para las prácticas 
pedagógicas daría oportunidad para generar debates colectivos y transformaciones fundamentadas, que posibiliten otra interpretación de la realidad, develando tramas sociales, históricas y políticas (Milstein, 2005). Nuestra intención es irrumpir en este escenario provocando el pliegue que permita una nueva praxis informada y crítica (Gorodokin, 2006), que sostenga las intervenciones didácticas e instale la lógica de problematizar las prácticas escolares.

Es el objetivo general de este artículo analizar las prácticas y las representaciones vinculadas a la comprensión lectora y producción textual en el 2 do. Ciclo de la Educación Primaria y en el Espacio de la Práctica de la Formación Docente en el área Prácticas del Lenguaje, desde el Instituto de Formación Docente № 22 “Dr. Adolfo Alsina” y para el caso de las Escuelas Primarias (EP) N 8 y $\mathrm{N}^{\circ} 59$ del distrito de Olavarría (Buenos Aires, Argentina), en el período 2016-2017. Se intenta dar respuesta a los siguientes interrogantes: ¿Cuáles son las prácticas cotidianas de enseñanza y de aprendizaje respecto de los procesos de lectura y escritura? ¿Cuáles son las intervenciones y estrategias didácticas que se ponen en marcha en estos procesos? ¿Cuáles son las representaciones de docentes y docentes en formación sobre las dificultades relativas a la lectura y escritura, y de qué modo impactan en la producción de propuestas didácticas?

\section{ESTADO DE LA CUESTIÓN Y CONSIDERACIONES TEÓRICAS}

Presentamos a continuación algunas investigaciones que han contribuido al conocimiento del problema. Se destacan particularmente los avances de Ana María Finocchio (2012) en su Maestría en Ciencias Sociales con orientación en Educación de FLACSO- Argentina. La autora define como su problema la enseñanza de la escritura en 6to. y $7 \mathrm{mo}$. grado de la escuela primaria a través de un estudio de cuadernos/carpetas de clase. El propósito es mirar la enseñanza de la escritura desde la cultura escolar y, en este caso en particular, desde uno de los objetos que conforman la cultura material de la escuela. Estas categorías teóricas son relevantes para nuestra investigación, ya que permiten pensar continuidades y cambios en los saberes que se transmiten, en las tecnologías que atraviesan las prácticas de enseñanza y en la materialidad de los objetos, entre otras dimensiones.

En el marco de las investigaciones promovidas por el INFD, Sergio Espósito y otros (2010) focalizan en las consignas escolares y los procesos cognitivos que promueven, en 2 do. Ciclo de la escolaridad primaria y en el campo disciplinar de las ciencias sociales. Sus conclusiones permiten ampliar las variables a atender en torno a nuestra segunda interrogante, que focaliza en las intervenciones y estrategias didácticas, entre ellas la formulación de consignas. El equipo concluye que son escasas las consignas de opinión relacionadas con la expresión y comunicación de ideas; predominan las consignas del tipo de reproducción, que llevan a transcripciones textuales de información, fomentando un aprendizaje superficial y poco significativo.

Además, esas consignas remiten a fotocopias descontextualizadas que llegan a los estudiantes sin referencia a la época y contexto de producción o que son copiadas de los libros de textos. No se evidenció tampoco la presencia de consignas que promovieran la reflexión acerca de sus propios procesos de aprendizaje, los puntos de partida y de llegada, las síntesis realizadas, es decir, las vinculadas al proceso de metacognición. En el análisis surge que no se fomenta, por 
tanto, la construcción de significados, la puesta en juego de estrategias de reorganización y trasformación de la información.

Los estudios citados nutren la propuesta que se desarrolló en torno a las prácticas y representaciones implicadas en la enseñanza de habilidades de escritura y comprensión lectora, en el caso particular del 2do. Ciclo de Educación Primaria y en sus complejas articulaciones con la formación docente. Utilizamos la lengua para organizar nuestra experiencia, categorizar el mundo, dar sentido a nuestras actividades cotidianas, relacionarnos con quienes nos rodean y construirnos como seres sociales. A través del lenguaje el sujeto construye su identidad social y cultural. Consideramos, entonces, una concepción del lenguaje en uso, que se lleva a cabo a través de la interacción verbal. Esta perspectiva implica opciones epistemológicas: la principal opción es pensar el lenguaje desde una dimensión dialógica, que permita explicar cómo el mundo social y natural son semantizados en y a través del discurso, en el proceso de comunicación intersubjetiva.

Comenzamos por redefinir el objeto de la enseñanza en el nivel analizado en términos de "Prácticas del Lenguaje", que remite, entre otras, a la teoría de la acción comunicativa de Habermas (1987). El interaccionismo socio-discursivo abona la idea de que las prácticas del lenguaje son prácticas culturales que no se reducen a las conductas lingüísticas, sino que incluyen rituales, usos y costumbres, materializadas en los textos como productos de la interacción social. En esta línea, J. P. Bronckart (2007) -formado en el pensamiento de Vygotski, Bruner y Piagetseñala la preocupación por la vinculación entre teoría y metodología, debate sobre la transposición didáctica e investiga las relaciones entre el lenguaje, pensamiento, el trabajo como acción y la formación como proceso.

Actualmente, este enfoque orienta un nuevo modo de aprendizaje de la gramática que supera al modelo estructural para destacar, en cambio, la gramática textual. Se propone desarrollar en la escuela situaciones de escritura que fomenten la reflexión metalingüística, a partir de la revisión y reescritura de borradores como instancias privilegiadas para el aprendizaje gramatical a través de ejercicios de construcción léxico-sintáctica. El propósito no es la enseñanza directa de la gramática, en tanto las reglas del sistema de la lengua, sino el empleo de los diversos recursos de ese sistema y la experimentación con el lenguaje como instrumento para configurar sentidos (Gaspar y Otañi, 2001).

Acerca de las aproximaciones a los procesos de lectura y de escritura, no podemos dejar de mencionar el libro de 1979 que Emilia Ferreiro publica con Ana Teberosky, Los sistemas de escritura en el desarrollo del niño, que tuvo una repercusión decisiva en la teoría y práctica de la alfabetización. En desarrollos sucesivos se replanteó la cuestión desde la perspectiva del sujeto que aprende, dando entrada así al niño piagetiano, un sujeto creador y verificador de teorías, y naturalmente activo en la construcción de conocimiento (Ferreiro, 1999).

Entre el ' 80 y el '90 surgen los estudios cognitivos, que se dan en el marco de la Psicología Cognitiva y de la Psicolingüística. Han construido modelos del procesamiento de la lectura y la escritura. Estos modelos permiten esbozar didácticas de la lectura que tengan en cuenta aspectos tales como la necesidad de trabajar con los alumnos la elaboración de inferencias frente a cada texto, la reelaboración de los escritos, la indagación de léxico desconocido u otras búsquedas del significado.

Delia Lerner (2001) entiende que es necesario hacer de la escuela una comunidad de lectores, que acudan a los textos buscando respuestas para los problemas que necesitan resolver. 
En este sentido, enseñar a leer y escribir trasciende ampliamente la alfabetización en sentido estricto. Transformar la enseñanza es un propósito central, porque se aspira a democratizar el conocimiento $y$, en particular, a ofrecer a todos los niños auténticas oportunidades de acceder a la cultura escrita, de formarse como lectores y escritores plenos (Lerner y Palacios, 1994; Lerner et al, 2009). Desde una perspectiva constructivista, las opciones pedagógicas deben favorecer situaciones didácticas apropiadas tanto a sus posibilidades cognoscitivas como al carácter social del aprendizaje, y que respondan a las características de la lengua escrita como objeto cultural.

Problematizar la formación de habilidades de escritura y comprensión lectora nos conduce a formular nuevas interrogantes acerca de las representaciones docentes, cómo devienen articuladoras de determinados modelos y modos de intervención didáctica, cuáles son los sentidos que actualizan en el marco de las situaciones escolares. El orden de lo representacional constituye un campo de convergencia de muy diversas tradiciones teóricas. Hernández Machuca (2012) ha llamado la atención respecto de que las representaciones, las concepciones y las creencias son categorías de estudio que refieren a dimensiones diferentes, no obstante, se las asumen como sinónimos debido a la dificultad de establecer sus límites.

En síntesis, las representaciones son individuales, cognitivas, en tanto que la persona se apropia de un conocimiento, recreándolo, pero son al mismo tiempo sociales, porque han sido construidas en el contexto de la sociedad. De allí que se actualizan, construyen y recrean en la interacción comunicativa cotidiana de los individuos (Ortiz Casallas, 2013). La educación, los medios de comunicación y las tecnologías digitales inciden con fuerza para generar consensos en torno a ciertas miradas hegemónicas sobre la realidad social. En el campo educativo, las representaciones sociales expresan tensiones y luchas por mantener posiciones dominantes a partir del desarrollo de ciertas prácticas y habitus largamente objetivados.

Finalmente, el problema de la alfabetización no puede quedar escindido de las múltiples experiencias que los niños producen en sus interacciones con las tecnologías de la información y la comunicación. Tal como enuncia el Diseño Curricular del Nivel Primario:

El uso de las TIC en entornos educativos implica la renovación del compromiso profesional docente a la luz de los nuevos escenarios de construcción de saberes. Es necesario incorporar los recursos digitales para formar sujetos protagonistas, tanto en lo educativo como en lo social. La innovación pedagógica no requiere de un docente tecnólogo, sino de un mediador que abra nuevas dimensiones de aprendizaje que no son posibles sin las TIC. Ya no se trata de transmitir información o datos, el objetivo es que los estudiantes desarrollen estrategias creativas y colaborativas para la resolución de problemas.

Coincidimos con Dussel y Quevedo (2010) cuando destacan que habría que pensar en la posibilidad de que estos lenguajes abren a la intervención, reescritura y cambio de sentido de los productos ya existentes. Nos preguntamos cómo están mediando las relaciones de los alumnos con la escritura y el aprendizaje escolar en su conjunto, qué tipos o modalidades de textualización involucran y cuáles son las variadas estrategias de intervención didáctica que tienden a capitalizar - o poner en tensión- esas prácticas y saberes en el ambiente del aula. 


\section{PROPUESTA METODOLÓGICA}

Este proyecto se enmarca en una investigación cualitativa, que responde a una concepción holística orientada a comprender en profundidad y desde la totalidad contextual el conjunto de significados que subyacen a los hechos educativos. La propuesta de un diseño exploratorio implica que los objetivos centrales se orientan al descubrimiento de categorías descriptivas y analíticas. También presupone que no existe un conocimiento amplio sobre el problema, por lo que se prevé que estas primeras aproximaciones sirvan de base a una investigación a posteriori, de carácter descriptivo-interpretativo y con vistas a dotar de mayor profundización y desarrollo a la teoría producida.

Dada la necesidad de superar el frecuente distanciamiento entre teoría y práctica, entre investigación básica y aplicada, nuestra investigación se inscribe en una propuesta que articula a ambas. Compromete a los participantes con su conocimiento práctico, profundizando la comprensión de los problemas en un proceso constante de autorreflexión que tiende a impactar en los procesos de enseñanza y los de aprendizaje, al tiempo que genera aportes significativos al campo teórico-disciplinar.

La problemática que nos ocupa revela una realidad socioeducativa dinámica, compleja y global, que resulta comprensible desde una perspectiva hermenéutica que se da gracias a la racionalidad dialógica con los sujetos (Scribano, 2008). La decisión metodológica fue diferenciar nuestro trabajo tanto de las investigaciones etnográficas, como de aquellas orientadas a la verificación o contrastación de hipótesis (inducción analítica). Este enfoque tiene la ventaja de potenciar la relación dialéctica entre la teoría y la práctica: el proceso no es lineal, sino que progresa constantemente a partir de la interacción entre el marco conceptual, la recolección y el análisis de los datos empíricos.

En consecuencia, la Teoría Fundamentada de Glaser y Strauss supone una doble estrategia: 1- de acuerdo al método comparativo constante, se realiza simultáneamente la codificación y el análisis, a fin de formular conceptos; 2 - el muestreo teórico permite llevar a cabo al mismo tiempo la recolección y el análisis de los datos (Vieytes, 2004).

La metodología del Análisis Textual no se restringe al análisis semio-lingüístico, sino que involucra los diversos materiales del corpus y su puesta en relación con sus contextos específicos de producción. Esta perspectiva entronca con la teoría de la acción comunicativa de Habermas, que remite a la idea de que el mundo cobra objetividad por el hecho de ser reconocido y considerado como tal por una comunidad de sujetos capaces de lenguaje y de acción. Se trata de un estudio de caso que aborda como universo de análisis el 2do. Ciclo de la Educación Primaria tomando como unidades a las escuelas asociadas EP $N^{\circ} 59$ y EP N ${ }^{\circ}$, en función de sus diversas características institucionales, culturales y pedagógicas. Sin implicar una determinación absoluta, estas condiciones materiales adquieren implicaciones en los modos de intervención de los maestros como en los resultados esperados de aprendizaje. Siendo ambas escuelas públicas, la EP $N^{\circ} 8$ presenta condiciones razonablemente adecuadas de rendimiento escolar, sus alumnos pertenecen a sectores socioeconómicos medios; en cambio, la EP $\mathrm{N}^{\circ} 59$ es una de las escuelas llamadas "periféricas", con mayores dificultades estructurales y socioeducativas.

Conforme a esta propuesta metodológica, consideramos tres tipos de instrumentos de recolección de datos: a- análisis de cuadernos, carpetas y ambiente alfabetizador; b- 
observaciones, registros de clases y planificaciones didácticas; y c- grupos focales de docentes en ejercicio, que apunten a complementar y profundizar la información recabada en los soportes escritos y los registros de clases.

En una investigación exploratoria, el muestreo teórico resultó especialmente útil porque permitió ir seleccionado los materiales de la muestra que pudieran producir mayor rendimiento teórico. Además de las fuentes documentales (carpetas, ambiente alfabetizador, planificaciones didácticas, etc.), priorizamos la entrevista grupal, por lo cual la selección de los informantes se basó en un diseño flexible donde lo importante no fue la cantidad de personas a entrevistar, sino el potencial de la información que aportó cada una en la comprensión teórica del tema.

Finalmente, los resultados que presentamos a continuación se organizan sobre la base de una matriz de datos que comprende tres dimensiones, con sus respectivas subdimensiones $y$ áreas de indagación:

1). Prácticas de lectura y escritura:

\subsection{Oralidad,}

1.2. Lectura,

1.3. Escritura.

2. Intervenciones didácticas:

2.1. Enseñanza de la lectura y escritura,

2.2. Diseño de la evaluación,

2.3. Uso de tecnología.

3. Representaciones docentes:

3.1. Área Prácticas del Lenguaje,

3.2. Rol docente,

3.3. Contexto familiar, cultural y socioeconómico.

\section{RESULTADOS Y PRESENTACIÓN DE LOS DATOS}

\section{1- Prácticas de lectura y escritura}

En principio, las decisiones didácticas se centran en habilidades asociadas a la literatura, no solamente en tanto contenidos prescriptivos sino en pos de fomentar competencias discursivas más amplias. Como profundizaremos luego, hay un predominio de los géneros literarios, especialmente cuentos, y el interés que estos generan en los alumnos suele ser potenciado para desarrollar la oralidad. En cambio, el empobrecimiento del vocabulario, las faltas de ortografía, las falencias en comprensión de consignas y producción de textos son problemas atribuidos a los códigos familiares, tecnológicos y juveniles. Así, cobran centralidad las tensiones que estos lenguajes alternativos entrañan: “...por ahí no cortar del todo lo que ellos traen, porque ellos tienen una cotidianeidad que por ahí no es la que se trabaja en la escuela pero que tenemos que incluir y entender cómo incluir en lo que es Prácticas del Lenguaje" (docente EP N 8). 
Estas afirmaciones pueden conducir a cierta subestimación poco objetivada de la competencia de oralidad, frente a las habilidades de la escritura caracterizadas como más complejas, de mayor impacto cognitivo o jerarquía social. Conforme a ello, difícilmente las habilidades orales puedan ser trabajadas a partir de intervenciones espontáneas, o bien de manera articulada en secuencias didácticas que incluyan también consignas de producción escrita. Aunque no hay correlación inmediata, estos binarismos parecen más arraigados en situaciones socioeducativas menos favorecidas: para los docentes en ejercicio de la EP $N^{\circ} 59$, la oralidad es "mucho más fácil", la pueden "pilotear", "remar" o "acomodar"; lo escrito "se complica", es "distinto", se transmite de "otra forma", etc.

El contraste es notable con los maestros residentes en ambas instituciones. La siguiente planificación expresa relaciones dinámicas entre la oralidad, la escritura y la lectura, las imágenes en tanto disparadoras del análisis, la implementación de distintos soportes que fomenten la curiosidad. La oralidad constituye una competencia compleja que merece un trabajo agudo, bajo claros propósitos didácticos.

Se trabajará con "Nana para un lobo miedoso" de Liliana Moyano. Se le entregará una copia a cada alumno y cada estrofa será leída por diferentes chicos. Luego, se presentará el texto en un afiche para poder analizarlo entre todos. Se mostrarán dos imágenes y los alumnos deberán elegir una que se relacione con los sentimientos expresados... (planificación EP $\mathrm{N}^{\circ}$ 8).

En las dificultades implicadas en la producción escrita se manifiestan, entre otros aspectos, los desfasajes con la expresión oral: "Mejorar la escritura, que es de lo más difícil (...), pero cuesta mucho, es más, desde la oralidad para llegar a un producto escrito, cuesta. Los alumnos están cada vez menos acostumbrados a hablar" (docente EP N 8 ).

El relato nos permite reconocer otras dos cuestiones. Por una parte, la convicción de que, a pesar (o debido a) las falencias de sus alumnos, es tarea inexcusable implementar estrategias adecuadas que los motive hacia niveles cada vez más complejos de aprendizaje. Por otra, esas iniciativas aparecen orientadas al trabajo con una diversidad de géneros discursivos. En el mismo relato: "Como estamos con Las mil y una noches, eligieron Los 40 ladrones, y bueno, cómo lo vamos haciendo... cómo lo haríamos si fuera una noticia policial (...) Y quedó una noticia re linda armada..." Pero lo que se valora es la producción escrita en sí, antes que los textos mediáticos, su propósito comunicativo, su funcionamiento retórico o ámbito específico de circulación, ya que estos temas suelen supeditarse a los géneros narrativos.

Quienes pertenecen a esta escuela ponderan la escritura en términos de composición textual, el trabajo con planificaciones y borradores que habiliten la autocorrección, la conciencia metalingüística, el monitoreo constante de lo producido. En otros grupos, las representaciones favorables hacia el modelo se contradicen con la escasa realización en la práctica. Se aduce como obstáculo la propia resistencia del alumno, sin que el docente se muestre capaz de involucrarlo en actividades que despierten en él mayor interés, apelen a su autoconfianza, aporten significatividad a ese esfuerzo de revisión y reescritura: los chicos "se aburren", "hasta se torna plomo". 
Nuevamente, verificamos un contraste con los docentes residentes. Así, una planificación áulica parte de la lectura de un cuento, para luego integrar varios componentes orientados a: 1elaborar borradores, 2- trabajar en grupo, 3- recuperar conceptos aprendidos, 4- articular distintos soportes didácticos, 5- inscribir lo producido en secuencias didácticas más amplias. La propuesta es que los alumnos en pareja deberán trabajar un personaje del cuento, "en borradores bajo la supervisión, guía y acompañamiento de la docente. La versión final de cada poesía será grabada con voz en off para poder ser compartidas en el encuentro de lectores..."

En torno a la lectura como subdimensión del análisis, se destaca la necesidad de incentivar el placer por ella cuando los alumnos son todavía "chiquitos" y "moldeables". Estas experiencias tienen un importante componente personal, ligado a intereses previos como a los entornos familiares. Ahora bien, investigaciones recientes demuestran que niños de sectores sociales más favorecidos, donde la lengua escrita ya existe en las familias como objeto cotidiano, se alfabetizan, pero no disfrutan necesariamente de la lectura (Kaufman et al, 2015). Los lugares por excelencia para promover esas experiencias lectoras siguen siendo el salón y la biblioteca, en continuidad con los hogares.

Las acciones docentes tienen por objeto movilizar ese interés. En el registro del ambiente alfabetizador (es decir, el conjunto de materiales y recursos disponibles en el salón), la Agenda de lectura comprende estos datos en un cuadro: "Fecha, cuento, autor, personajes y lugar." $Y$, respectivamente, "1/03- Misterio en la biblioteca- Verónica Chamorro- Enzo, Pascualito- la biblioteca. Y 31/1- Los duendes- Hermanos Grimm- monstruo, los duendes, el bebé- una casa."

A este tipo de materiales, subyace una intencionalidad didáctica que tiende a que el alumno identifique componentes básicos de lo leído, para ser recuperados en las clases subsiguientes, a la vez que desarrolle articulaciones con la escritura (en carpetas, afiches y cartelera) y la oralidad (debates, evaluaciones grupales).

En consonancia con las planificaciones antes analizadas, entre docentes residentes se destacan actividades de prelectura, que se anticipan a la lectura individual y grupal del cuento. También entienden que, en grupos que manifiestan severas dificultades de comprensión lectora, es necesario implementar la lectura grupal y asistida, que parece tener mejores resultados que la lectura individual: "A veces, individualmente los nenes no registran con facilidad cuál es el error, la relectura es compleja, también les cuesta muchísimo leer comprensivamente, y también les cuesta muchísimo leer en voz alta..." (EP N59). Volveremos sobre este punto.

\section{2- Las intervenciones didácticas}

La enseñanza de la lectura y escritura se presenta organizada predominantemente por proyectos en el plano de la planificación como primera intervención. Ahora bien, surge de los registros en carpetas de alumnos y registros de observación de clase, la existencia de múltiples disruptores de la cultura institucional que alteran en la práctica la continuidad y el ritmo en la enseñanza: actos, jornadas, actividades extraescolares, etc. La fragmentación emerge como síntoma. El impacto es menor durante el período de residencia del docente en formación, ya que el docente del espacio del Campo de la Práctica aparece sosteniendo la "mirada" sobre la secuenciación y complejización de las actividades propuestas, sin perder de vista el propósito comunicativo. 
En cuanto a las dinámicas de interacción, identificamos: a- trabajos en pequeños grupos, bactividades colectivas, c- actividades en pareja, d-actividades individuales. En el trabajo en grupos no se observan criterios de selección de miembros ni explicitación de tareas para cada uno. Un segundo aspecto reside en la formulación de consignas claras: proponer lectores rotativos, dividir el texto en unidades de sentido, orientar la búsqueda y selección de información.

Una docente de la EP $N^{\circ} 59$ escribe en el pizarrón: "En grupos buscamos, leemos y seleccionamos información y nos preparamos para exponer". Los alumnos se dirigen a la biblioteca del aula y luego interpelan:

A 1: -Seño, en este libro no hay información. No habla de las poesías.

A 2: -En nuestros libros tampoco...

D: -Chicos, tienen que mirar primero el índice y luego ir a las páginas donde habla sobre ese tema. Además, hay que leer y subrayar lo más importante.

Conceptualizada en los términos de "decir" o "hacer" (Lerner, 2001), la noción de intervención didáctica cobra fuerza en relación a los silencios, que no configura una ausencia sino una forma particular de intervención. Anticiparse a tales preguntas puede resultar de una cuidada planificación, como entre los docentes en formación de la misma escuela:

Hoy vamos a realizar la producción de los afiches publicitarios. Para ello, vamos a necesitar el plan textual que realizamos con la información que debe tener el afiche y la información del destino turístico que cada grupo buscó (...) ¿Qué tenemos que tener en cuenta? La organización del texto y la imagen. Tipo de letra. Información del plan textual...

En el trabajo colectivo, el docente suele dialogar con tres o cuatro alumnos, los más activos. Escribe en el pizarrón y luego les indica copiar en las carpetas. En contraste, un docente residente de la EP N 59 apunta a la inclusión de todas las voces: "- ¿Y el del cuento? (interpela a una alumna que mantiene una actitud expectante). Azul... vení. Nunca escribís... nunca me hablás” (con tono dulce).

En lo que respecta a materiales didácticos, "el salón de clases debe contar con materiales que habiliten múltiples actos de lectura y escritura. Por eso, es muy importante que en las aulas haya diversos y numerosos portadores de textos (Kaufman, 2012, p. 79), como libros, revistas, afiches, juegos, diarios, etc. Sin embargo, en ambas escuelas asociadas se observa la pobreza de tales portadores y la ausencia de biblioteca del aula con acceso libre; es el docente quien habilita la "apertura del mueble" con que se restringe simbólicamente a la biblioteca y sus usos necesarios.

Por otra parte, las intervenciones didácticas revelan dificultades en el dominio de conocimientos disciplinares y pedagógicos. En ocasiones expresan imprecisiones o "reducciones" conceptuales en torno a los géneros para leer o escribir. Por ejemplo, en una planificación en la EP $N^{\circ} 8$ aparece la novela como género diferenciado de otros textos narrativos. Si observamos este registro:

Podemos decir que las acciones son verbos, a las palabras que designan características o cualidades de las cosas, personas, lugares, acciones son adjetivos, ¿sí?, Y las palabras que 
designan cosas, nombres, objeto, lugar, personas son sustantivos, por ejemplo, si yo hablo del amor también es una cosa, es un sustantivo, pero no es una cosa que tenga forma...

Las falencias en los saberes pedagógicos resultan aún más extendidas. Las situaciones de interacción oral para la promoción de la lectura tienden a asumir una modalidad grupal, pero con escasa participación de los alumnos o por parte de unos pocos. Las oportunidades para ampliar el vocabulario y adquirir conceptos metalingüísticos son restringidas, en tanto las preguntas tienen un bajo nivel de exigencia cognitiva (Medina Morales et al, 2015). Tras la lectura colectiva, pregunta la maestra antes citada: “¿Qué características tiene el personaje (Hércules)? Ésa es re fácil, porque recién dijimos entre todos, serían sus cualidades, y ¿quién es el personaje?"

En tanto segunda subdimensión, la evaluación convoca una práctica reflexiva, sobre la base de los procesos de seguimiento, control y valoración de los conocimientos adquiridos. ¿Cuáles son los criterios e instrumentos que efectivamente organizan estas intervenciones? Las carpetas resultan particularmente significativas, como conservación de lo registrado y espacio de interacción entre docentes y alumnos. Constituye así un dispositivo que da cuenta de "unas prácticas discursivas asociadas a la productividad del alumno y a la actividad escolar: las consignas o propuestas de tareas, la resolución de las tareas y la evaluación o corrección de las mismas" (Finocchio, 2014, p. 15). Esta carpeta es el lugar de interpelación al alumno, registra situaciones de autoevaluación y la elaboración de borradores que podrían propiciar a niveles mayores de conciencia metalingüística.

ACUERDO DE CORRECCION 2016. Así vamos a corregir en el año:

Mayúsculas = Punto aparte (flecha) Error de ortografía (línea) Sangría O. No te olvides que cada vez que escribas la seño va a ayudarte haciendo las marcas de corrección, vos tenés que emplearlas al pasar a la carpeta las versiones finales (4to. Año, EP Nº).

Sobre todo, entre docentes en ejercicio, verificamos una desarticulación entre consignas y falta de continuidad, la no adecuación al año de cursada, comentarios sin explicaciones claras de los errores ni de cómo superarlos. En torno a las condiciones de reescritura, no parece útil la consigna "revisen los textos", sin sugerir pistas que guíen las revisiones. En contraste, otras intervenciones focalizan en los aspectos gramaticales, pero no de manera parcelada u orientada solo por los recursos de la lengua, sino integrados en el ejercicio de las prácticas del lenguaje.

Por último, nos detendremos brevemente en las tecnologías implicadas en la enseñanza del lenguaje: Internet, computadoras y teléfonos celulares. En tanto estos últimos están por completo ausentes, observamos actividades con netbooks, aprovechando la disponibilidad del aula móvil. La utilización es predominantemente instrumental: se valora positivamente en tanto herramienta, para buscar información, usar el procesador de textos o escuchar audios. En una carpeta de 4to. Año: "Leo y sigo la lectura del cuento: Con el sol entre los ojos, de Elsa Bornemann. Escuchamos el audio en la net". Estas intervenciones utilizan de modo complementario a las tecnologías disponibles, favoreciendo la escucha en el marco de una segunda oralidad (Ong, 2000), pero adolecen de proyecciones más amplias y evitan discutir los sentidos sociales de esa integración. 
Si bien no hay un uso extendido, algunas experiencias incentivan la producción de conocimiento, como intervenciones en blogs, presentaciones audiovisuales o contenidos, canciones o foto historias. En tanto prácticas socialmente determinadas, la lectura y la escritura están mediadas por esas experiencias digitales, dentro y fuera de la escuela. Si los niños se muestran entusiastas y motivados, los saberes previos que pueden ser capitalizados dependen de las condiciones de acceso en el hogar (las diferencias socioeconómicas de base resultan notables en este sentido).

A la par de las disposiciones favorables al uso pedagógico, la búsqueda de información genera tensiones. Además de que las escuelas no suelen contar con conectividad, los docentes ponen en duda la utilidad de "copiar y pegar", pero no explicitan criterios ordenadores que permitan trabajar con sus alumnos la valoración de la fiabilidad de las fuentes, la selección y jerarquización, los usos críticos de la información. Internet constituye un problema, con evasivas vinculaciones con la enseñanza: "A veces, cuando ellos traen información de la casa es el trabajo que se hace en el aula, porque ellos googlean y lo imprimen y lo traen, así como lo bajaron, pero, bueno, el trabajo después es del docente..." Al decir de Perelman (2011), identificar las fuentes de Internet demanda la construcción de hipótesis de lectura más costosas que en el papel. Pero el desarrollo de competencias comunicativas implica que el alumno logre acceder a las diversas voces, aprender a detectar qué ocultan y qué revelan y cómo pueden ajustarlas a los fines del aprendizaje escolar.

\section{3- Las representaciones docentes}

En los términos de Hernández Machuca (2012), las representaciones constituyen configuraciones sociales normativizadas que permean e influyen a una colectividad y que, en el caso de los profesores, permite entender la trama de significaciones que atribuyen a sus prácticas y a las condiciones generales que las determinan. El rol docente es depositario de los sentidos del "buen maestro", del lugar atribuido a la planificación didáctica y a los modos de construcción de autoridad en el aula.

El ambiente alfabetizador del 4to. año de la EP $N^{\circ} 8$ registra una concepción integral y articulada entre áreas, como en lo relativo al recorte temático en Prácticas del Lenguaje y Ciencias Sociales. Un afiche elaborado por los alumnos incluye el título Abuelas de Plaza de Mayo, fotografías alusivas, la reseña "El 24/03/76 ocurrió el último golpe cívico-militar".

En los modelos de enseñanza y evaluación subyacentes se sostienen propuestas que responden a usos novedosos e interactivos de los materiales, la orientación hacia un trabajo colectivo, formas dialógicas de participación áulica, más frecuentes y fundadas en la planificación -antes que como hecho espontáneo- entre docentes en formación. Se trata de actividades que presentan otros tiempos y lógicas de desarrollo, expresando las tensiones con las intervenciones de docentes en ejercicio, que presentan menos previsión didáctica. Baste como ejemplo el registro de una clase de la $\mathrm{EP} \mathrm{N}^{\circ} 59$, el intercambio entre docente residente y alumnos a partir de la escucha literaria:

D: - ¿Qué tipo de libro era éste que ya les había presentado?

A: -Una antología. 
D: -Claro, porque había muchos cuentos en él... ¿Para qué hicimos las características de la bella y la bestia?

A: -Para saber cómo eran...

(La docente lee el cuento La bella durmiente. Todos escuchan atentamente...)

Reconocemos aquí esquemas representacionales que se sostienen en supuestos acerca de las definiciones de la práctica lectora, en qué consisten esas competencias y cómo pueden ser desarrolladas. Retomando a Lerner (2001), si la centralidad de la lectura en voz alta deriva de una concepción del aprendizaje que focaliza en las manifestaciones externas de la actividad intelectual, la necesidad de control hace sentir su influencia, ya que evaluar tal aprendizaje resultaría más penoso si predominaran las situaciones de lectura silenciosa. En la ponderación de ese control reposa en buena medida la construcción de autoridad docente, como las condiciones material-simbólicas de intervención que le son favorables. Desde una dimensión cognitiva, la lectura pone en un plano importante los saberes previos con que los alumnos abordan los textos, lo que explicaría por qué un mismo texto admite representaciones mentales diversas. Esto no excluye el hecho de que aprender a leer con otros supone procesos individuales construidos en el marco de prácticas colectivas, contexto que marca la misma práctica de la lectura complejizando su carácter (Archanco, 2013).

En las concepciones acerca del alumno, convergen, por una parte, las representaciones acerca del contexto familiar, cultural y socioeconómico (las dificultades estructurales, la crisis de valores, la ausencia de los padres, etc.) y, por otra, del diseño curricular, las connotaciones negativas que asume la articulación inter-ciclos haciendo foco en la Unidad Pedagógica (Res. Prov. $\mathrm{N}^{\circ}$ 81/2013). Esta se convierte en obstáculo cuando, llegado al 2do. Ciclo, el alumno no ha adquirido las competencias requeridas para avanzar en sus aprendizajes: expresión oral, habilidad en la escritura, interpretar textos y consignas, utilizar la cursiva y vocabulario adecuado, reconocer clases de palabras, etc.

La tensión entre el compromiso personal hacia la mejora educativa, implicado en la dimensión afectiva y profesional del rol docente, y la tendencia a depositar las responsabilidades en ese "otro" generalizado (la educación, el sistema, la familia), atraviesa los discursos y adquiere en ellos efectos paradojales. Este relato abunda en repeticiones, a la vez que presenta el desplazamiento del nosotros inclusivo hacia las construcciones impersonales que permiten justificar las razones de la alfabetización tardía.

Un concepto de leer, leer es leer, leo, espero, no está pensando en lo que lee, pero no comprende. Sí, mi hijo lee, pero ¿comprende lo que lee? Ahí es donde estamos fallando, yo personalmente tengo mi concepto, creo que la unidad pedagógica tiene su valor, pero a su vez creo que la educación se relajó... (EP Nº 8).

La contraparte de los aspectos negativos del área es la ponderación de la transversalidad. Resulta significativo que esta valoración positiva aparece referida en todos los discursos y constituye un poderoso organizador de las prácticas en ambas escuelas. Además, fundamenta de manera tácita la identidad docente en relación con otras áreas: asumir que las Prácticas del Lenguaje atraviesan otros campos de conocimiento $y$, por lo tanto, median sus condiciones de 
apropiación, sirve de argumento al momento de jerarquizar la formación disciplinar o de validar su lugar en la institución. Otros términos que califican el área son "fundamental", "abarcativa", "vértebra", "atraviesa", etc.

Una de las cuestiones fue cómo pueden los alumnos expresarse oralmente y por escrito en todas las áreas. Y que puedan producir desde todas las áreas. Producción, mucha producción oral y escrita en todas áreas, en Matemáticas, explicando el procedimiento... (docente EP N8).

Porque el estudio de la lengua te sirve para trabajar las demás áreas, naturales, matemáticas, sociales. Nosotras en Prácticas del Lenguaje practicamos lectura, practicamos escritura. Y la escritura y la lectura las necesitamos para las otras áreas (docente EP $N^{\circ} 59$ ).

En algunos casos, los significados de la transversalidad se materializan en los espacios de intervención didáctica, donde se conjugan la disposición a innovar, la dimensión lúdica, el desarrollo de proyectos colectivos. Una de las profesoras describe un trabajo con cartas, a través de la investigación en el área de Sociales: "Hicieron una carta donde hicieron un juego y los chicos tenían que elaborar una carta que tenía que ver con la historia del bicentenario, los chicos partieron de un crimen, expresaban distintos personajes de la historia..." Su compañera destaca la motivación que genera en los alumnos enviar las cartas por correo, una experiencia social que prácticamente ellos desconocen y que recibe el activo acompañamiento de las familias: "Porque esas cartas llegaron a su mamá, a su papá, creando un vínculo afectivo con ellos, a su hermanita, después los papás respondieron que les había agradado la carta, que no se la esperaban porque fue sorpresa..."

Otra característica positiva que define al área es el propósito comunicativo, "la lengua viva, en uso." Este propósito comunicativo no es meramente prescriptivo, debe efectivizarse en la práctica como parte constitutiva de la tarea docente, orientada a generar la reflexión metalingüística. Al mismo tiempo, refuerza la importancia medular que se atribuye al área, especialmente en contextos sociales desfavorables donde el dominio competente del lenguaje constituye un factor importante de igualación de oportunidades.

\section{CONCLUSIONES}

Interpelar las prácticas y las representaciones vinculadas a la lectura y escritura en el 2 do. Ciclo de la Educación Primaria, renueva las tensiones entre docentes en actividad y aquellos que inician sus intervenciones en el área. En estas configuraciones se realiza cotidianamente la cultura material de la escuela, que excede, resignificándolos, los modos esperados de alfabetización. Acerca de las prácticas cotidianas de enseñanza y de aprendizaje respecto de los procesos de lectura y escritura, los docentes destacan las falencias generalizadas de sus alumnos: las faltas ortográficas, las dificultades en la escritura y en la comprensión de consignas, la pobreza del lenguaje, etc. En general, son los docentes residentes quienes tienden a recuperar en sus 
planificaciones los intereses y habilidades que detentan los niños en torno al dominio de otros códigos, como los familiares y tecnológicos.

Otro punto de tensión reside en el lugar dilemático de la oralidad. Por una parte, verificamos una subestimación de la misma frente a la escritura, concebida como práctica más compleja y elaborada o de mayor impacto sociocognitivo. Por otra, la oralidad se restringe al momento posterior a la lectura, como intercambio sobre lo leído. A su vez, en el terreno de la práctica, la lectura y la escritura están supeditadas a la literatura como ámbito privilegiado de producción. Introducir otros géneros, mayormente vinculados a los medios de comunicación, aparece estrictamente supeditada a los géneros literarios. La elaboración de borradores recibe valoraciones positivas por parte de los docentes, pero su realización concreta está sujeta a las concepciones, en ocasiones prejuiciosas, sobre el alumno ("se aburre" o "no le gusta" escribir). En contraste, los docentes residentes suelen integrar en sus secuencias didácticas una diversidad de acciones, tales como la elaboración de borradores, la revisión de conceptos, el trabajo en equipo y la autoevaluación.

La subdimensión de la lectura condensa varios tópicos: a- las modalidades de lectura, en el caso de docentes en actividad, con predominio de la lectura grupal y asistida; b- las actividades de prelectura, resultantes de una planificación adecuada y en el marco de secuencias didácticas; c- la lectura por placer y no solo como parte de la resolución de consignas (estas dos últimas, con cierta sistematicidad entre docentes residentes); y d- la carpeta, como espacio de registro escrito y valoración de esas prácticas. Así, las carpetas devienen fundamentales dispositivos para el análisis de un mundo de saberes creado a través de la escritura, como de las representaciones del leer y del escribir construidas en la cultura escolar (Chartier citado en Finocchio, 2012).

Conforme a nuestra segunda interrogante, acerca de las intervenciones didácticas que se ponen en marcha en estos procesos, observamos la fragmentación y discontinuidad en la secuenciación y complejización de las propuestas. Más allá de la planificación, aparece como el núcleo sintomático de la organización de la enseñanza en las aulas, producto de disruptores propios de la cultura institucional y la pérdida de atención sobre las previsiones didácticas. Esta fragmentación se suspende relativamente durante la residencia de los practicantes, sobre la base de la mirada del docente del Espacio del Campo de la Práctica y especialista del área.

$Y$ en las intervenciones concretas, la formulación de la consigna aparece mayormente desprovista de complejidad y orientación del accionar del alumno, generando una dilatación del tiempo didáctico y la improvisación en las tareas. Expresiones de ello son las dinámicas de interacción grupales o colectivas sin claridad en las consignas, que devienen en ausencias de respuestas o en respuestas no esperadas. En los proyectos de las docentes en formación se visualiza, en cambio, la centralidad de esta construcción discursiva con intencionalidad pedagógica. Paralelamente, se advierten dificultades en el dominio de conocimientos disciplinares y pedagógicos que impactan en las posibilidades de acción. Las competencias en torno a lo metalingüístico son un punto crítico, así como la amplitud del campo.

La evaluación comprende aristas complejas: las percepciones de cantidad por sobre calidad, de control por sobre valoración, de marcación del error, pero sin correlato en el aprendizaje, entre otras, aparecen en los discursos y en la materialidad de las carpetas. Los docentes en formación parecen poner mayor atención a la evaluación en su carácter procesual, de seguimiento de los 
aprendizajes más allá de los códigos de corrección, bajo propuestas de autoevaluación, coevaluación y metaevaluación que habiliten reflexiones metalingüísticas sobre lo producido.

Las TIC ofrecen diversas modalidades de uso pedagógico, con predominio de lo instrumental y la escucha literaria, si bien algunas propuestas novedosas avanzan hacia la producción de contenidos, el trabajo colaborativo y las prácticas de lectura y escritura. Se utilizan las netbooks del aula móvil, en tanto los celulares están ausentes y los accesos de Internet aparecen relegados a los hogares. Consideramos dos implicaciones importantes: que esos usos están generalmente determinados por la disponibilidad material-simbólica en los entornos familiares, y que las actividades de búsqueda se consideran un problema antes que condiciones de posibilidad (la pérdida de control, las acciones de "copiar y pegar"). Los docentes, tanto en ejercicio como en formación, no suelen explicitar criterios de selección, validación y utilización crítica de la información, a pesar de que tales experiencias suponen, en sus opiniones, valiosas oportunidades.

Finalmente, las representaciones median los sentidos de la autoridad pedagógica, las articulaciones entre áreas, los tipos y modos de utilización de los materiales disponibles. Si bien la experiencia dota al docente de fundamentales herramientas con sentido reflexivo, también expresa modelos arraigados, al tiempo que valores negativos sobre el diseño curricular y las características de sus alumnos, todo aquello que parece excusarlos de la falta de innovación pedagógica. De ningún modo puede asumirse que esta tendencia a innovar sea estructurante de la formación, pero son los futuros docentes quienes planifican bajo el seguimiento de sus tutores, lo que les permite desenvolverse con mayor previsión didáctica, a la vez que capitalizar situaciones espontáneas.

Las representaciones altamente favorables acerca del área Prácticas del Lenguaje están extendidas en el conjunto de los maestros, en torno a dos ejes semánticos: la transversalidad (y con ello, su importancia como mediadora en la adquisición de todo conocimiento) y el propósito comunicativo, la adecuación del uso del lenguaje a las diversas situaciones y la reflexión metalingüística que tales situaciones reclaman. Implica asumir que la escritura y la lectura configuran prácticas sociales, no solamente habilidades discursivas ni reductibles al trabajo con la literatura.

En suma, el ámbito literario presenta un alto grado de libertad de interpretación, apela a la propia subjetividad y pone a los sujetos en espacios concretos de creación. Pero es necesario considerar las experiencias previas de los alumnos, aquellas que se vuelven alternativas a las escolares, convocando una pluralidad de modos de aprendizaje. Formar en el uso autónomo del lenguaje implica comprender críticamente este campo cultural y, con ello, promover en el otro "un conocimiento activo, capaz de cuestionarse, criticarse y verificar permanentemente la coherencia de lo que se va construyendo" (Gaspar y Archanco, 2006, p. 45). Sugerimos entonces incorporar el enfoque de la multialfabetización ya que amplía los alcances de la alfabetización tradicional; brindaría más recursos para la comunicación, así como enriquecería las propuestas de lectura y escritura en el desarrollo de proyectos que incluyan múltiples soportes y formatos textuales. 


\section{BIBLIOGRAFÍA}

Archanco, P. (2013) Sobre la práctica de la lectura en la escuela: supuestos, continuidades y rupturas. Buenos Aires: FLACSO Virtual.

Bronckart, J. P. (2007) Desarrollo del lenguaje y didáctica de las lenguas. Buenos Aires: Miño y Dávila.

Dussel, I. y Quevedo, L. A. (2010) VI Foro latinoamericano de educación. Educación y nuevas tecnologías: los desafíos pedagógicos ante el mundo digital. Buenos Aires: Santillana.

Espósito, S., Barrera, E., Gallo, M. R., Martínez, V. y otros (2010) Las consignas escolares como dispositivos para el aprendizaje. ISFD N6. Neuquén: INFD. Ministerio de Educación.

Ferreiro, E. (1999) Cultura escrita y educación. México: Fondo de Cultura Económica.

Ferreiro, E. y Teberosky, A. (1979) Los sistemas de escritura en el desarrollo del niño. México: Siglo XXI.

Finocchio, A. M. (2012) Cambios y continuidades en la enseñanza escolar de la escritura. Ponencia a las Jornadas de jóvenes investigadores en educación. FLACSO- Argentina.

Finocchio, A. M. (2014) Cambios recientes de la enseñanza de la producción escrita en la escuela primaria argentina. Tesis de la Maestría en Ciencias Sociales. FLACSO- Argentina.

Gaspar, M. y Archanco, P. (2006) Lenguaje y lectura desde la escuela. Caracas: IESALC UNESCO.

Gaspar, M. y Otañi, L. (2001) Sobre la gramática, en Entre Líneas. Buenos Aires: FLACSO Manantial.

Gorodokin, I. C. (2005) La formación docente y su relación con la epistemología. Revista $\begin{array}{lllll}\text { Iberoamericana de } & 37 & \text { (5), } & \text { 1-10. }\end{array}$ https://doi.org/https://doi.org/10.35362/rie3752691

Habermas, J. (1987) Teoría de la acción comunicativa. Madrid: Taurus.

Hernández Machuca, D. C. (2012) Estado del arte sobre la concepción de concepciones docentes y su relación con la enseñanza de la escritura en primaria. Revista Infancias Imágenes. 11 (1), 99-106. https://doi.org/10.14483/16579089.4557

Kaufman, A. M. (coord.) (2012) Leer y escribir: el día a día en las aulas. Buenos Aires: Aique.

Kaufman, A. M., Castedo, M., Teruggi, L. y Molinari, C. (2015) Alfabetización de niños: construcción $e$ intercambio. Experiencias pedagógicas en jardín de infantes y escuela primaria. Buenos Aires: Aique. 
Lerner, D. (2001) Leer y escribir en la escuela: lo real, lo posible y lo necesario. México: Fondo de Cultura Económica.

Lerner, D. y Palacios, A. (1994) El aprendizaje de la lengua escrita en la escuela. Buenos Aires: Aique Didáctica.

Lerner, D., Stella, P. y Torres, M. (2009). Formación Docente en Lectura y Escritura. Buenos Aires: Paidós.

Medina Morales, L., Valdivia Barrios, A., Gaete Moscoso, R y Galdames Franco, V. (2015) ¿Cómo enseñan a leer los profesores de $1^{\circ}$ y $2^{\circ}$ básico en un contexto de evaluación de desempeño docente en Chile? Estudios Pedagógicos. XLI (1), 183-198, Santiago de Chile. https://scielo.conicyt.cl/pdf/estped/v41n1/art11.pdf

Milstein, D. (coord.) (2005) La investigación educativa en la formación docente de la Provincia de Buenos Aires. Revista RedIPARC. 1 (1).

Ong, W. (2000) Oralidad y escritura. Tecnologías de la palabra. México: FCE.

Ortiz Casallas, E. M. (2013) Las representaciones sociales: un marco teórico apropiado para abordar la investigación social educativa. Revista de Ciencias Sociales. XIX (1). Universidad del Zulia. Maracaibo, Venezuela.

Perelman, F. (coord.) (2011) Enseñando a leer en Internet: pantalla y papel en las aulas. Buenos Aires: Aique.

Scribano, A. (2008) El proceso de investigación social cualitativo. Buenos Aires: Prometeo.

Vieytes, R. (2004) Metodología de la investigación en organizaciones, mercado y sociedad. Epistemología y técnicas. Buenos Aires: Ed. de las Ciencias Sociales. 